\title{
Corticosteroid Actions on Amino Acid-mediated Transmission in Rat CA1 Hippocampal Cells
}

\author{
Marian Joëls' ${ }^{1}$ and E. Ronald de Kloet ${ }^{2}$ \\ 'Department of Experimental Zoology, University of Amsterdam, Amsterdam, and ${ }^{2}$ Center for Biopharmaceutical \\ Sciences, Leiden University, Leiden, The Netherlands
}

We here describe actions mediated by mineralo- and glucocorticoid receptors (MRs and GRs, respectively) on intracellularly recorded synaptic responses, evoked in rat $\mathrm{CA} 1$ pyramidal cells in vitro by stimulation of the Schaffer collaterals. Neurons in slices from adrenalectomized (ADX) rats, that is, where MRs and GRs are unoccupied, showed a synaptic response consisting of an EPSP, followed by a fast and a slow IPSP; the responses were apparently similar to those in slices from sham-operated rats. However, in the ADX rats, repeated electrical stimulation over a period of 80 min resulted in a gradual decline of the firing probability for synaptically driven action potentials and of the slow IPSP amplitude. Nonsynaptic responses (e.g., membrane potential, accommodation, and afterhyperpolarization) were stable during the $80 \mathrm{~min}$ period. Application of $3 \mathrm{~nm}$ aldosterone between 20 and $\mathbf{4 0}$ min after impalement of cells in slices from ADX rats, thus activating predominantly MRs, yielded stable synaptic and nonsynaptic responses for at least $1 \mathrm{hr}$ after the onset of the steroid application. By contrast, corticosterone (30 $\mathrm{nm}$ ), which occupies GRs in addition to MRs, reduced the amplitude of both the EPSP and slow IPSP, and the firing probability of synaptically driven action potentials, within $\mathbf{2 0}$ min; nonsynaptic properties remained stable. Similar results were obtained with the selective glucocorticoid RU 28362. The EPSP and fast and slow IPSPs of neurons in slices from ADX rats impaled with a time lag of 1-4 hr after the steroid application did not differ significantly from the responses of neurons impaled before steroid application. By contrast, a GR-mediated increase of the afterhyperpolarization amplitude in the same group of cells developed only after the 1-4 hr time lag. We conclude that steroid receptor occupation, particularly of MRs, is important for the maintenance of amino acid-mediated transmission in the CA1 area during repeated stimulation. Additional GR occupation depresses the amino acid-mediated transmission. The GR effect is rapid in onset and short-lived in contrast to the GRmediated increase of the afterhyperpolarization, and may thus represent a different mode of action by which corticosteroids can affect excitability in the CA1 region.

Received July 31, 1992; revised Mar. 9, 1993; accepted Apr. 13, 1993.

We thank Drs. Hesen, Karst, and Sutanto for assistance and Drs. Wadman and Somjen for critical reading. Roussel-Uclaf is acknowledged for the gift of RU 38486 and RU 28362, and Organon Int. for the gift of corticosterone and aldosterone.

Correspondence should be addressed to Marian Joëls, Department of Experimental Zoology, University of Amsterdam, Kruislaan 320, 1098 SM Amsterdam, The Netherlands.

Copyright (c) 1993 Society for Neuroscience $0270-6474 / 93 / 134082-09 \$ 05.00 / 0$
[Key words: mineralocorticoid receptor, glucocorticoid receptor, corticosterone, EPSP, fast IPSP, slow IPSP, CA 1 area, hippocampus, intracellular recording, rat]

Corticosterone, the endogenous corticosteroid hormone of the rat, is released from the adrenal gland into the circulation. It passes the blood-brain barrier and binds to intracellular receptors in the brain (for reviews, see McEwen et al., 1986; de Kloet, 1991). Two receptor types have been distinguished, based on binding characteristics and primary structure: the mineralocorticoid receptor (MR), which binds corticosterone with a high affinity $\left(K_{d} \sim 0.5 \mathrm{nM}\right)$, and the glucocorticoid receptor (GR), with an approximately 10 -fold lower affinity for corticosterone (Reul and de Kloet, 1985; Arriza et al., 1987; Funder et al., 1988). Due to the differential aftinity, low corticosterone levels will predominantly occupy MRs, while high concentrations of corticosteronc will additionally activate GRs (Reul and de Kloet, 1985). After binding of corticosterone to the receptors, the steroid-receptor complex acts as a transcription factor on specific genes. In addition to the intracellular receptors, membrane receptors may be present in the brain (Orchinik et al., 1991).

Pyramidal neurons in the rat CAl area contain both MRs and GRs (van Eekelen et al., 1988; for review, see de Kloet, 1991). In previous studies we and others have shown that activation of the steroid receptors affects the neuronal excitability in the CA1 region. Thus, MR occupation decreases whereas GR activation increases with a considerable time lag the accommodation and afterhyperpolarization (AHP) of CA1 neurons associated with short depolarizing pulses (Joëls and de Kloet, 1989, 1990; Kerr et al., 1989); protein synthesis is required for the development of these steroid-mediated actions (Karst and Joëls, 1991). Furthermore, MR and GR activation interferes with transmittcr responses, mediated via G-protein-coupled receptors such as the $\beta 1$-adrenergic (Joëls and de Kloet, 1989) and $5-\mathrm{HT}_{\mathrm{la}}$ receptors (Joëls et al., 1991). In general the actions of the steroid, both on intrinsic and on transmitter-evoked cellular responses, were such that MR activation served to maintain or even enhance cellular activity in the CA1 region whereas additional GR activation led to a suppression of excitability (Joëls and de Kloet, 1992).

The activity of the CAl neuronal network depends, in addition to the intrinsic properties of the cells of the network, to a considerable degree on the amino acid-mediated transmission. Thus, the CA1 pyramidal neurons receive a major excitatory glutamatergic input through the Schaffer collaterals (for review, see Lopes de Silva et al., 1990). Local inhibition takes place via feedforward and feedback projections of GABAergic interneurons (Knowles and Schwartzkroin, 1981; Alger and Nicoll, 
1982a). For a better appraisal of the role of corticosterone on the excitability in the CAl area, it is necessary to evaluate the actions of the steroid hormone on the amino acid-mediated transmission.

During the past decade several extracellular studies have described effects of corticosteroid hormones on the amino acidmediated input to CAl pyramidal cells. Thus, Reiheld et al. (1984) showed that in particular low concentrations of corticosterone enhanced the population spike in slices from adrenalectomized (ADX) rats, within $10 \mathrm{~min}$. By contrast, Vidal et al. (1986) found a relatively rapid reduction of the population spike, with high corticosterone concentrations in slices from intact rats. These seemingly conflicting data may be explained by an interesting series of experiments by Soumireu-Mourat and coworkers, showing that low corticosterone concentrations in $\mathrm{BALB} / \mathrm{c}$ mice enhance the population spike amplitude via $\mathrm{MR}$ activation whereas high concentrations, via GR, decrease the population spike (Rey et al., 1987, 1989). The GR-mediated actions appear at lower corticosterone concentrations if the extracellular Ca level is raised (Talmi et al., 1992), supporting a role of calcium in GR-mediated effects (Kerr et al., 1989). Alternatively, the conflicting data in the earlier studies may be due to the use of ADX animals, since Doi et al. (1991) described corticosterone-dependent changes in the CA1 population spike upon adrenalectomy.

Several phenomena may underlie the steroid-induced effects on the population spike evoked by repeated stimulation. For instance, the steroids could affect the resting membrane potential of the CAl cells. Second, corticosterone may affect active properties of the CA1 pyramidal cells, such as the threshold for action potentials. Third, the corticosteroid hormones could interfere with the glutamate- or GABA-mediated transmission, either pre- or postsynaptically. This is supported by a recent study of Zeise et al. (1992) showing that very high doses of corticosterone depress particularly the $\mathrm{GABA}_{\mathrm{A}}$ receptor-mediated IPSP. In the present study, we have employed intracellular recording methods to study the effect of MR and GR activation on synaptically evoked EPSPs and IPSPs, and on intrinsic membrane properties of CAl pyramidal cells. We studicd possible fast effects of the steroids by comparing CA1 cell responses before, during, and up to $1 \mathrm{hr}$ after a brief ( $20 \mathrm{~min}$ ) steroid application in vitro. In a second series of experiments we investigated delayed steroid actions by comparing responses of neurons recorded before and $1-4 \mathrm{hr}$ after steroid administration.

\section{Materials and Methods}

Preparation of the tissue. Male Wistar rats ( $n=60$, TNO-Zeist, 120$160 \mathrm{gm}$ ) were adrenalectomized or sham-operated as described before (Ratka et al., 1988; Joëls and de Kloet, 1990). The animals were kept for 4-7 $\mathrm{d}$ in an animal house with an alternating light (8.00 A.M. to 8.00 P.M.)/dark (8.00 P.M. to 8.00 A.M.) cycle, and received food and water (sham) or saline (ADX) ad libitum. On the day of the experiments, the animals were transferred to a novel environment (new cage) and decapitated after 30-60 min. The trunk blood was collected for later analysis of the plasma corticosterone level with a radioimmunoassay. Animals with less than $1 \mu \mathrm{g}$ corticosterone $/ 100 \mathrm{ml}$ plasma were considered to be successfully adrenalectomized. After decapitation, the brain was removed from the skull and dipped in ice-cold buffer of the following composition (in mM): $\mathrm{NaCl}, 124 ; \mathrm{KCl}, 3.5 ; \mathrm{NaH}_{2} \mathrm{PO}_{4}, 1.25 ; \mathrm{MgSO}_{4}$. $7 \mathrm{H}_{2} \mathrm{O}, 1.5 ; \mathrm{CaCl}_{2}, 2 ; \mathrm{NaHCO}_{3}, 25 ;$ and glucose, 10 . Transverse slices $(350 \mu \mathrm{m})$ from the dorsal hippocampus were cut on a tissue chopper. The slices were then transferred to the recording chamber, where they were continuously submerged $(2 \mathrm{ml} / \mathrm{min})$ by warmed $\left(32^{\circ} \mathrm{C}\right)$, oxygenated $\left(95 \% \mathrm{O}_{2}, 5 \% \mathrm{CO}_{2}\right)$ buffer. Corticosterone, aldosterone (Organon Int.
Ltd., Oss, The Netherlands), the selective GR agonist RU 28362, and GR antagonist RU 38486 (Roussel-Uclaf, Romainville, France) were dissolved in $90 \%$ ethanol as a $1 \mathrm{~mm}$ stock solution for each experiment. Immcdiatcly before testing, the steroids were diluted to the intended concentration in oxygenated buffer and then added to the superfusion medium.

Recording and stimulation. Neurons in the pyramidal cell body layer of the CAl area were impaled with a glass, $4 \mathrm{M} \mathrm{K}$-acetate-filled micropipette $(80-150 \mathrm{M} \Omega)$. The signal was transferred, amplified, and filtered with conventional methods as described elsewhere (Joëls and de Kloet, 1990). For analysis, data were plotted on a Gould colorwriter, fed into a Gould $2200 \mathrm{pen}$ recorder, and/or saved on a Vetter videocassette recorder. Only neurons displaying typical characteristics of pyramidal cells (Schwartzkroin, 1975), a stable resting membrane potential of at least $-60 \mathrm{mV}$, input resistance of at least $20 \mathrm{M} \Omega$, and action potential of at least $80 \mathrm{mV}$ were incorporated in the present study. Synaptic responses were evoked by a stimulation electrode placed on the Schaffer collaterals. The stimulation electrode consisted of two stainless stecl, Trimel-coated wires $(60 \mu \mathrm{m}$ in diameter) through which we applied monophasic pulses of $150 \mu \mathrm{sec}$. Only experiments in which tnaxinal synaptic responses were obtained with a stimulation intensity of less than $200 \mu \mathrm{A}$ were included in the study. The fluid level in the bath was consistently kept at the same level, throughout each experiment.

Experimental protocol. In each CAl pyramidal cell we established the resting membrane potential, input resistance, the afterhyperpolarization (AHP) cvoked by a $50 \mathrm{msec}$ depolarizing pulse of $0.5 \mathrm{nA}$, and the number of spikes induced by a $500 \mathrm{msec}$ depolarizing current pulse of $0.5 \mathrm{nA}$ (accommodation). In addition, we established the synaptically evoked excitatory and inhibitory potentials. Typically, strong synaptic stimulation evoked an action potential superimposed on an EPSP, followed by a fast IPSP (fIPSP) and a slow IPSP (SIPSP; see Fig. 1). This agrees with data from literature (for review, see Nicoll et al., 1990) and represents the glutamatergic response mediated predominantly via $\alpha$-amino-3-hydroxy-5-methyl-4-isoxazolepropionic acid (AMPA) receptors (EPSP), the GABAergic response mediated via the GABA ${ }_{A}$ receptor (fIPSP), and GABAergic response mediated via the GABA $A_{B}$ receptor (sIPSP). Since the reversal potential for the fIPSP is between -70 and $-75 \mathrm{mV}$ (Dingledine and Gjerstad, 1980; Alger and Nicoll, $1982 \mathrm{~b}$; see also Table 1), small spontaneous or steroid-induced shifts in rcsting membrane potential may result in relatively large changes of the fIPSP amplitude. For this reason, we chose to record the synaptic responses at two fixed membrane potentials reached by injecting current through the recording pipette. We selected the membrane potential at which the EPSP amplitude could be measured in the absence of a fIPSP, that is, at the reversal potential for the fIPSP $\left(E_{\text {r.fIPSP }}\right)$, and the potential at $7 \mathrm{mV}$ depolarized from this reversal potential $\left(E_{r, \mathrm{nPSP}}+7\right)$, which was usually around the resting membrane potential (see Fig. 1). The stimulus intensity that was just subthreshold for evoking action potentials at $E_{r, n \text { Psp }}$ was designated as "maximal" intensity. While the maximal intensity was just subthreshold for action potentials at $E_{r, \text { flpsp }}$, it usually was suprathreshold at $E_{r, \text { nesp }}+7$. Because putative steroid-mediated increases of synaptic responses may remain unnoticed with maximal stimulation, we also recorded responses with a half-maximal stimulus intensity. For each of the four stimulation conditions, we established averages of four sweeps in order to minimize the influence of small variations between successive, synaptically induced responses. The interval between successive sweeps was approximately $7 \mathrm{sec}$ and was kept constant during the entire recording session. The EPSP amplitude that was used for comparison of groups was recorded at $E_{\text {r.fPsp }}$ with maximal and half-maximal stimulation. The fIPSP and sIPSP were established as the first and second hyperpolarizing phases, respectively, from the maximal stimulation at $E_{\text {r.fIrsr }}+7$; the sIPSP was also measured at $E_{r \text { rpsp. }}$. We also quantified the transitional shift (TS) between the fIPSP and sIPSP, by interconnecting the peak amplitudes of the fIPSP and sIPSP as shown in Figure 1.

In neurons where we studied short-term effects of the steroids, we recorded responses to synaptic stimulation once every $10 \mathrm{~min}$, for a total of $80 \mathrm{~min}$. Thus, we recorded synaptic responses for $20 \mathrm{~min}$ before steroid application (at $t=0,10$, and $20 \mathrm{~min}$ ), during the steroid treatment (at $t=30$ and $40 \mathrm{~min}$ ), and up to $40 \mathrm{~min}$ after steroid application was terminated (at $t=50,60,70$, and $80 \mathrm{~min}$ ). Aldosterone, corticosterone, and RU 28362 were applied for $20 \mathrm{~min}$, between $t=20$ and $t$ $=40 \mathrm{~min}$. In addition to the synaptic responses, we also established the input resistance, AHP amplitude, and accommodation at the end of the steroid perfusion $(t=40 \mathrm{~min})$ and $40 \mathrm{~min}$ later $(t=80 \mathrm{~min})$, at resting 


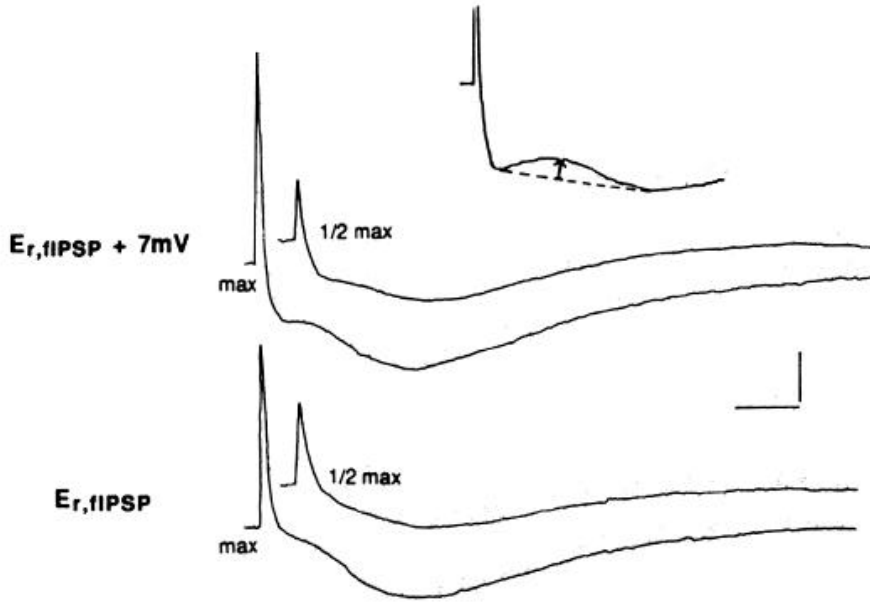

Figure 1. Experimental protocol for studying synaptic responses in CA1 pyramidal neurons. We first established the reversal potential for the fIPSP $\left(E_{r, \text { nPSP }}\right)$ and a potential that was $7 \mathrm{mV}$ depolarized from this reversal $\left(E_{\text {rnpsp }}+7\right)$, by injecting DC through the recording pipette. At $E_{\text {r.npsp }}$ we selected the stimulus current intensity that was just subthreshold for the induction of an action potential (max; 0 action potentials out of four stimuli) and the half-maximal current intensity ( $1 /$ 2 max). At the depolarized potential the maximal stimulus intensity was usually suprathreshold for the induction of an action potential (four action potentials out of four stimuli). Inset, For the quantification of the transitional shift between the fIPSP and sIPSP we connected the peak of the fIPSP and sIPSP and established the maximal amplitude of the depolarizing shift (arrow). All traces are averages of four sweeps, plotted on a Gould colorwriter. Action potentials are truncated. Calibration: $5 \mathrm{mV}$ (4.3 $\mathrm{mV}$ for inset), $100 \mathrm{msec}(87 \mathrm{msec}$ for inset).

membrane potential. The data obtained for nonsynaptic and synaptic responses at $t=40$ and $80 \mathrm{~min}$ were statistically compared with the data at the start of the experiment $(t=0 \mathrm{~min})$ with a paired Student's $t$ test. The experiments in slices from sham rats and in slices from ADX rats (with or without steroids) were randomly performed.

For the study of long-term effects, we recorded resting membrane potential, input resistance, AHP and accommodation, and synaptic responses in neurons before steroid application and compared these with the values obtained in different neurons in the same slice $1-4 \mathrm{hr}$ after a 20 min steroid application. The values of all groups were first tested with a one-way analysis of variance; if this test indicated that there were differences between the experimental groups $(p<0.05)$, the steroidtreated groups were compared with the ADX-group with an unpaired $t$ test.

\section{Results}

In total, we recorded from 137 neurons in the pyramidal cell body layer of the CAl area. These neurons displayed typical characteristics of pyramidal cells in vitro (Schwartzkroin, 1975), such as a resting membrane potential between -65 and -70 $\mathrm{mV}$, resistance between 45 and $50 \mathrm{M} \Omega$, very little spontaneous activity, strong accommodation of the spike firing frequency during a depolarizing current pulse, and a clear AHP following the termination of the depolarizing current pulse (see Table 1). Synaptic stimulation of the Schaffer collaterals in slices from ADX rats typically evoked an EPSP followed by an fIPSP, which peaked around $30 \mathrm{msec}$, and an sIPSP, which reached a maximum at approximately $200 \mathrm{msec}$ (see, e.g., Fig. 1). Directly after impalement of the cell, the responses were apparently similar to those obtained in the sham-operated animals that have an intact pituitary-adrenal axis (see Table 1).

We first tested the stability of the synaptic and nonsynaptic properties of neurons in ADX slices over a period of $80 \mathrm{~min}$ and next examined the changes in these properties as a result

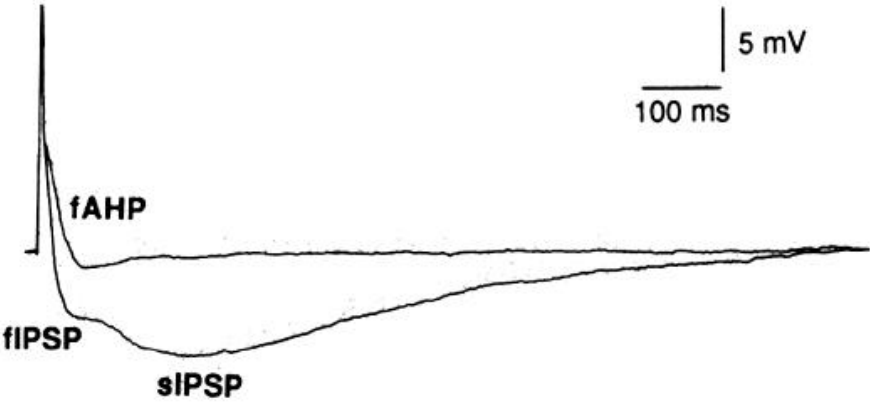

Figure 2. Comparison between synaptically and current-induced hyperpolarizations in the same CAl neuron. The response induced by a short current injection through the recording pipette is superimposed on a synaptic response at $E_{\text {r.npsp }}+7$ with maximal current intensity. Typically, the current-induced response evoked only a rather small, fast AHP, while no slow AHP was observed.

of corticosteroid treatment. Previously we had shown that particularly the slow AHP in CA1 neurons is under control of corticosteroids (Joëls and de Kloet. 1989, 1990). Since the peak amplitude of the fIPSP and SIPSP coincides in time with the peak of the fast AHP and slow AHP (Hotson and Prince, 1980; Gustafsson and Wigstrom, 1981; Lancaster and Nicoll, 1987), we first needed to establish how much of the fIPSP and sIPSP amplitude at $E_{\text {r.nPSP }}+7$ was actually caused by the AHPs, evoked by the preceding EPSP and spike. To test this, we compared the synaptic response with the cellular response to a brief depolarizing current injection evoking a single action potential, at the same membrane potential (Fig. 2). It appeared that a brief current-induced depolarization of similar duration as the EPSP resulted in a fast AHP that amounted to only $23.7 \pm 4.3 \%$ (mean \pm SEM, $n=10$ ) of the fIPSP in the same cell, while in no case did we observe a slow AHP. Therefore, we assume that possible effects of the steroids on the fast and particularly slow AHP probably did not interfere to a great extent with steroidmediated actions on the synaptically induced IPSPs.

\section{Short-term effects}

Over a recording period of $80 \mathrm{~min}$, resting membrane potential, input resistance, AHP amplitude, and accommodation did not change significantly in CA1 neurons of slices from ADX animals (data not shown). As to the synaptic responses, three observations were made (see example in Fig. $3 a$ and averaged data in Figs. 4, 5). First, the amplitude of the EPSP (both at maximal and half-maximal intensity) was slightly but not significantly reduced after repeated stimulation; the fIPSP was not changed. Second, the amplitude of the sIPSP was significantly reduced, particularly at $E_{\text {r.npsp }}+7$. Since we found that only approximately $20 \%$ of the IPSPs can be attributed to the induction of a fast AHP at $E_{\text {r.npsp }}+7$, we examined at which point in time the averaged amplitude of the sIPSP was decreased by more than $20 \%$. It appeared that the amplitude of the sIPSP at $E_{\text {r.nPsp }}+7$ was decreased by more than $20 \%$ from $60 \mathrm{~min}$ after the start of the recording onwards. Finally, the probability for inducing synaptically driven action potentials at $E_{\text {r.npsp }}+7$ decreased significantly over time. This decrease in synaptically evoked spikes was not accompanied by a change in the spike threshold $(n=$ 5; Fig. $3 b$ ).

Administration of $3 \mathrm{nM}$ aldosterone between 20 and $40 \mathrm{~min}$ after impalement of the cells, which was previously shown to evoke MR-mediated actions (Joëls et al., 1991), changed this 

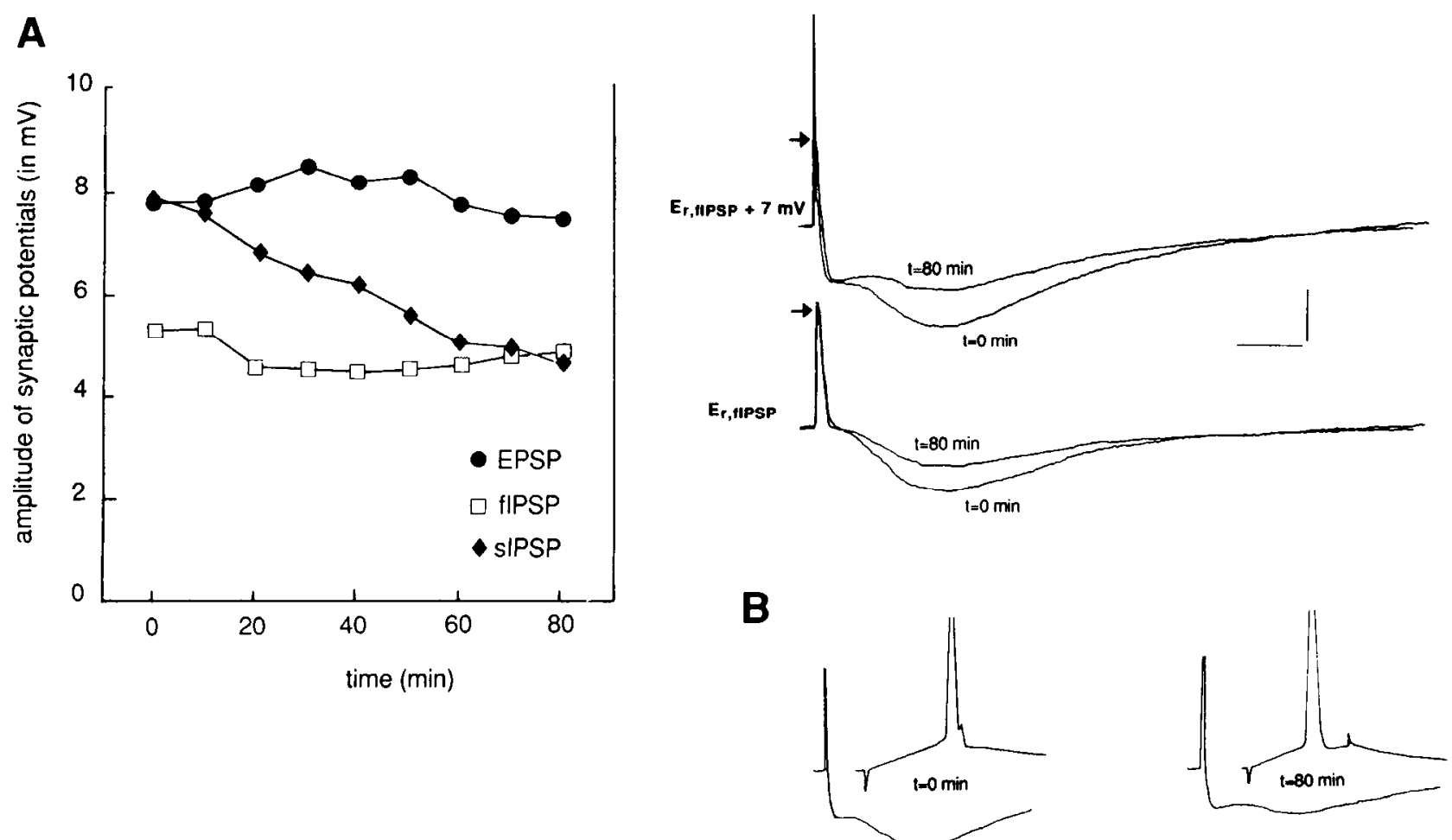

Figure 3: Changes in synaptic responsiveness in a slice from an ADX rat, over a period of 80 min. $A$, Typical example of synaptic responses recorded over time from a CAl pyramidal neuron in a hippocampal slice of an ADX rat. The amplitude of the maximal EPSP at $E_{r \text { npsp }}(\theta)$ changed little during the $80 \mathrm{~min}$ recording period. Similarly, the fIPSP recorded at $E_{r, \mathrm{nPs}}+7 \mathrm{mV}(\square)$ remained stable over the entire period. Yet, the amplitude of the sIPSP at Er,fIPSP $+7 \mathrm{mV}(\$)$ gradually declined. For this particular neuron the probability for evoking a synaptically induced action potential declined from 1 at $t=0 \mathrm{~min}$ to 0 at $t=40$ and $t=80 \mathrm{~min}$; the input resistance was 46,52 , and $52 \mathrm{M} \Omega$, respectively, at $t=0$, 40 , and 80 min. Representative synaptic responses recorded shortly after impalement of the neuron $(t-0$ min) and after 80 min are shown on the right. Arrows indicate the amplitude of the EPSP after $80 \mathrm{~min}$. Note that at $E_{r, \mathrm{IPSP}}+7$ no more action potentials were evoked after 80 min. $B$, Synaptic responses (left traces at $t=0$ and $t=80 \mathrm{~min}$ ) in another CA1 cell. The number of synaptically evoked spikes was reduced from four of four stimuli at $t=0 \mathrm{~min}$ to one of four at $t=80 \mathrm{~min}$ and the amplitude of the sIPSP was reduced. In the same cell the threshold for the induction of an action potential with DC current injection $(0.4 \mathrm{nA}$ for $10 \mathrm{msec})$ was not changed. Calibration for synaptic responses in $A$ and $B: 5 \mathrm{mV}$, 100 msec; all synaptic responses are averages of four sweeps. Calibration for current-induced action potentials in $B: 20 \mathrm{mV}, 5 \mathrm{msec}$.

situation (see example in Fig. 6; see also Figs. 4, 5). A small but significant $(p<0.05)$ depolarization was observed over time (from $-68.0 \pm 1.0 \mathrm{mV}$ at $t=0 \mathrm{~min}$ to $-64.0 \pm 1.4 \mathrm{mV}$ at $t$ $=80 \mathrm{~min}$ ), whereas input resistance, accommodation, and the amplitude of the AHP were not significantly affected. With respect to the synaptic responses we observed that the amplitude of the EPSP and fIPSP remained stable over time (see example in Fig. 6; sce also Figs. 4, 5). In contrast to the synaptic responses in untreated slices from ADX rats, the probability for inducing a synaptically driven action potential at $E_{r \text {.rpsp }}+7$ did not decrease over time, when slices were treated for 20 min with aldosterone. The amplitude of the sIPSP at $E_{r, \mathrm{IPSP}}+7$ but not at $E_{\text {r.nPsP }}$ decreased significantly after repeated synaptic stimulation; the averaged decrease in amplitude did not amount to more than $20 \%$ during the entire 80 min recording period.

If we applied $30 \mathrm{~nm}$ corticosterone, a concentration that probably occupies both MRs and GRs (Reul and de Kloet, 1985), cellular responses changed in several respects over time (see example in Fig. 7). First, the EPSP amplitude at maximal and half-maximal intensity was significantly reduced (Figs. 4, 5). Second, the SIPSP in contrast to the fIPSP was reduced both at $E_{r, \text { IIPSP }}$ and at $E_{\text {r.fIPSP }}+7$. The averaged decrease of the sIPSP at $E_{r, \text { IPSP }}+7$ reached a value of $20 \%$ at $60 \mathrm{~min}$ after the start of the recording. Finally, the number of synaptically evoked action potentials was greatly reduced. All changes in synaptic responses were already significant at 20 min after steroid application was started. Membrane potential, input resistance, accommodation, and AHP did not change significantly during or after corticosterone application, when compared with the values obtained in the same neurons before steroid administration. If we used RU 28362, a selective GR agonist (Philibert and Moguilevski, 1983), instead of the mixed agonist corticosterone, similar changes in synaptic responscs wcre observed, although here the decrease in EPSP amplitude was only observed at half-maximal stimulus intensity (Fig. 4). The averaged decrease of the sIPSP amplitude at $E_{\text {rfipsp }}+7$ already exceeded a value of $20 \%$ at 50 min after the start of the recording. Nonsynaptic responses were not affected significantly by RU 28362 .

We also recorded synaptic and nonsynaptic responses during an $80 \mathrm{~min}$ period in neurons from sham-operated rats. We selected rats that had comparable plasma corticosterone levels (i.e., $\sim 10 \mu \mathrm{g}$ corticosterone $/ 100 \mathrm{ml}$ plasma) at the moment of decapitation. Neurons $(n=6)$ in slices from sham-operated rats that were recorded over a period of $80 \mathrm{~min}$ displayed quite stable synaptic responses (Figs. 4, 5), resembling the stability observed in the aldosterone-treated slices from ADX rats. Thus, the amplitude of the EPSP, both with maximal and with halfmaximal stimulus intensity, and the amplitude of the fIPSP did not changc significantly over a recording period of $80 \mathrm{~min}$. Similarly, the probability for inducing a synaptically driven ac- 

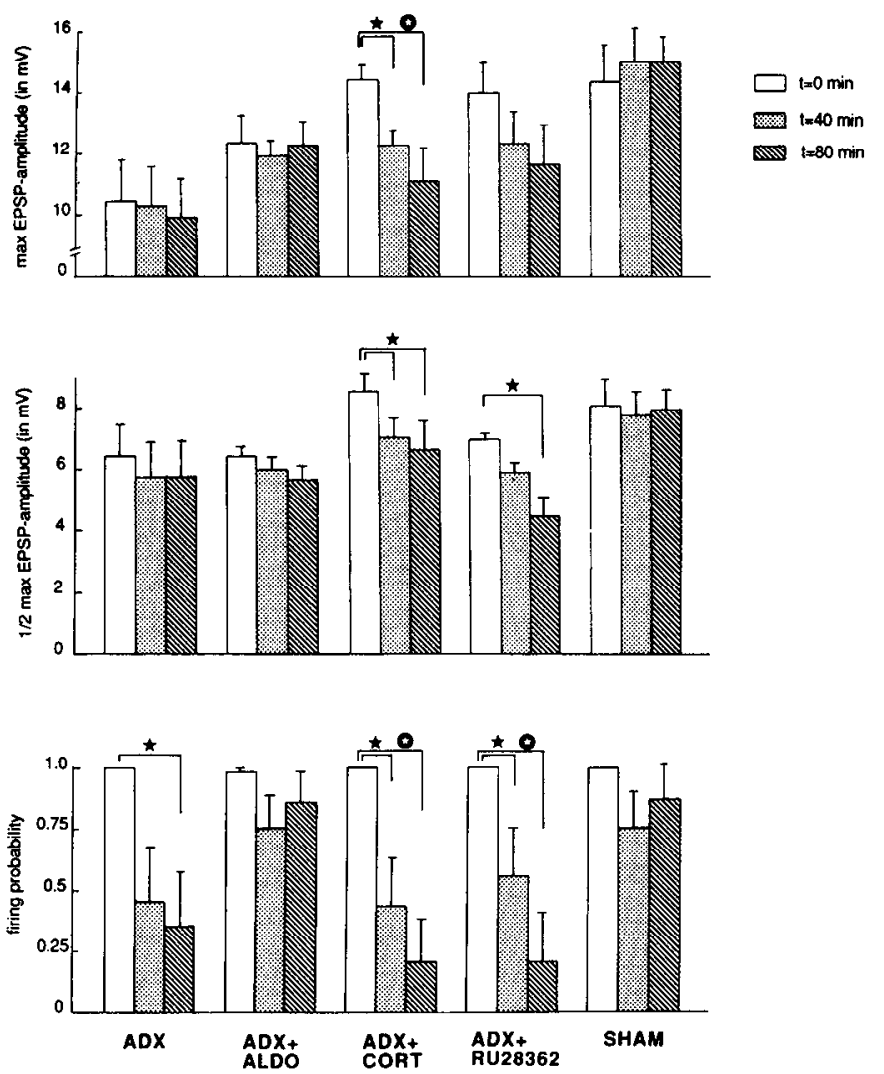

Figure 4. Steroid-dependent changes in excitatory synaptic responses over an 80 min recording period: bar histograms showing the averaged maximal EPSP amplitude + SEM (upper panel), the half-maximal EPSP (middle panel), and probability for evoking a synaptically driven action potential (lower panel). The data were collected from neurons in slices from ADX rats $(A D X ; n=7)$, in slices from ADX rats that were perfused for $20 \mathrm{~min}$ (between 20 and $40 \mathrm{~min}$ after the start of the recording period) with $3 \mathrm{nM}$ aldosterone $(A D X+A L D O ; n=6)$, with $30 \mathrm{nM}$ corticosterone $(A D X+C O R T ; n=6)$, or with $30 \mathrm{~nm}$ RU 28362 $(A D X+R U 28362 ; n=5)$ and in slices from sham-operated controls ( $S H A M ; n=6)$. The bars represent the synaptic parameters, at three time points: (1) at the start of the 80 min recording period (open bars); (2) at 40 min after the start of the experiment (stippled bars), that is, 20 min after onset of steroid hormones, in the case of steroid-treated ADX slices; (3) at 80 min after the start of the recording period (hatched bars), that is, $60 \mathrm{~min}$ after onset of the steroid application, in the case of steroid-treated ADX slices. The synaptic responses recorded at 40 or $80 \mathrm{~min}$ after onset of the recording period were compared with the values at $t=0 \mathrm{~min}$, with a paired Student's $t$ test $(\star, p<0.05 ; \otimes, p$ $<0.01)$.

tion potential at $E_{r \text { nPSP }}+7$ remained stable over the entire recording period. The amplitude of the sIPSP at $E_{r . \mathrm{fPSP}}+7$ was significantly reduced after $80 \mathrm{~min}$. However, this decrease did not exceed a value of $10 \%$ during the entire $80 \mathrm{~min}$ recording session. Nonsynaptic responses, such as the resting membrane potential, input resistance, accommodation, or amplitude of the AHP, were not significantly altered over time.

The averaged $E_{r, \mathrm{IPSP}}$ for the various groups ranged from -72.5 to $-74.8 \mathrm{mV}$, at the beginning of the $80 \mathrm{~min}$ recording period. As gradual shifts in the $E_{r . f P S P}$ during the recording session of 80 min may affect the amplitudes of the EPSP and the sIPSP over time, we examined if the $E_{r, n P S P}$ remained stable during the recording sessions. In none of the experimental groups did we observe changes in the $E_{r, n p s p}$ over the recording period of 80 $\min$. Neurons where we tested the effect of ethanol only, for 20

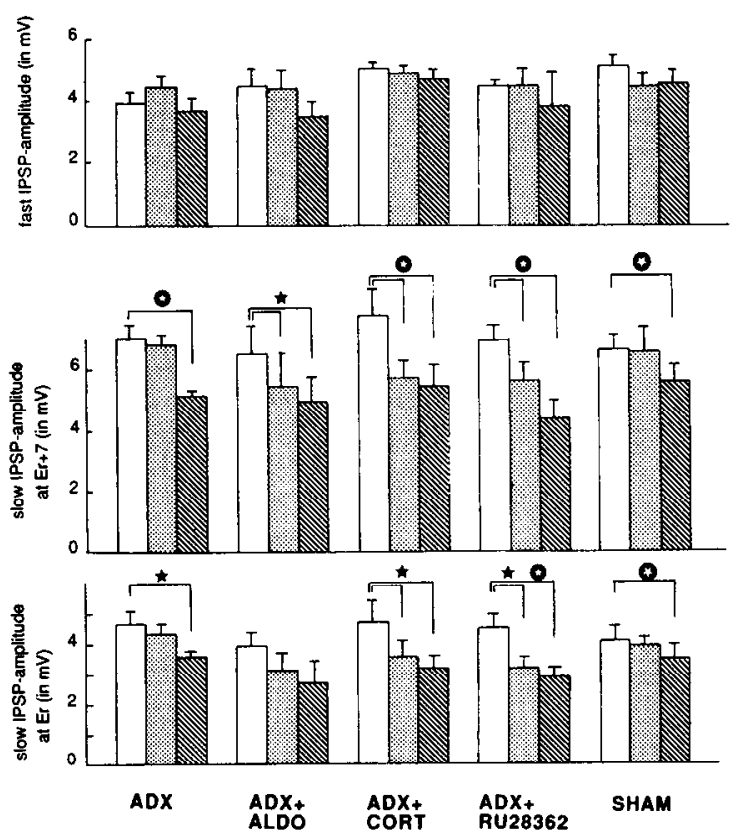

Figure 5. Steroid-dependent changes in inhibitory synaptic potentials over an $80 \mathrm{~min}$ recording period: bar histograms showing the averaged amplitude + SEM for the fIPSP (upper panel) and the sIPSP at $E_{\text {r.fIPSP }}+7$ (middle panel) and at $E_{r \text { npsp }}$ (lower panel). The open bars represent the values obtained at the start of the experiment; the stippled bars, the data after $40 \mathrm{~min}$, that is, $20 \mathrm{~min}$ after onset of a 20 min steroid perfusion (in the steroid-treated slices from ADX rats); and the hatched bars, the data after $80 \mathrm{~min}$, that is, $60 \mathrm{~min}$ after onset of the steroid application. Experimental groups and statistics are as described in the Figure 4 caption.

min (up to $0.05 \%$, vehicle for steroids; $n=10$ ), were indistinguishable from the non-cthanol-trcatcd ADX group, with respect to their synaptic and nonsynaptic properties (not shown).

\section{Long-term effects}

In Table 1 , the intrinsic and synaptic properties of CA 1 neurons recorded 1-4 hr after steroid application, in the absence of repeated stimulation, are compared to the values obtained before steroid treatment. Resting membrane potential and input resistance varied little between groups. However, the AHP amplitude was clearly enhanced in slices from ADX rats superfused for 20 min with corticosterone or RU 28362, and in slices from sham-operated rats, when compared to the neurons in untreated ADX slices.

No significant changes were observed for either the EPSP fIPSP, or SIPSP amplitudes, irrespective of repeated stimulation of other cells in the same slice, $1-4 \mathrm{hr}$ earlier. Although the EPSP tended to be somewhat smaller in slices from ADX rats, and the fIPSP and particularly the sIPSP were relatively small in the aldosterone-treated slices, these differences did not attain statistical significance. By contrast, the TS (transitional shift) between the fIPSP and sIPSP was significantly larger in slices from sham-operated rats or slices from ADX rats treated with RU 28362 when compared to the nontreated ADX slices (Fig. 8). If stimulation intensities required to evoke maximal responses were compared for a group of neurons recorded after steroid treatment with the group of neurons recorded in the same set of slices before steroid application, no significant or consistent changes were observed in any of the groups (as tested with a paired $t$ test). 

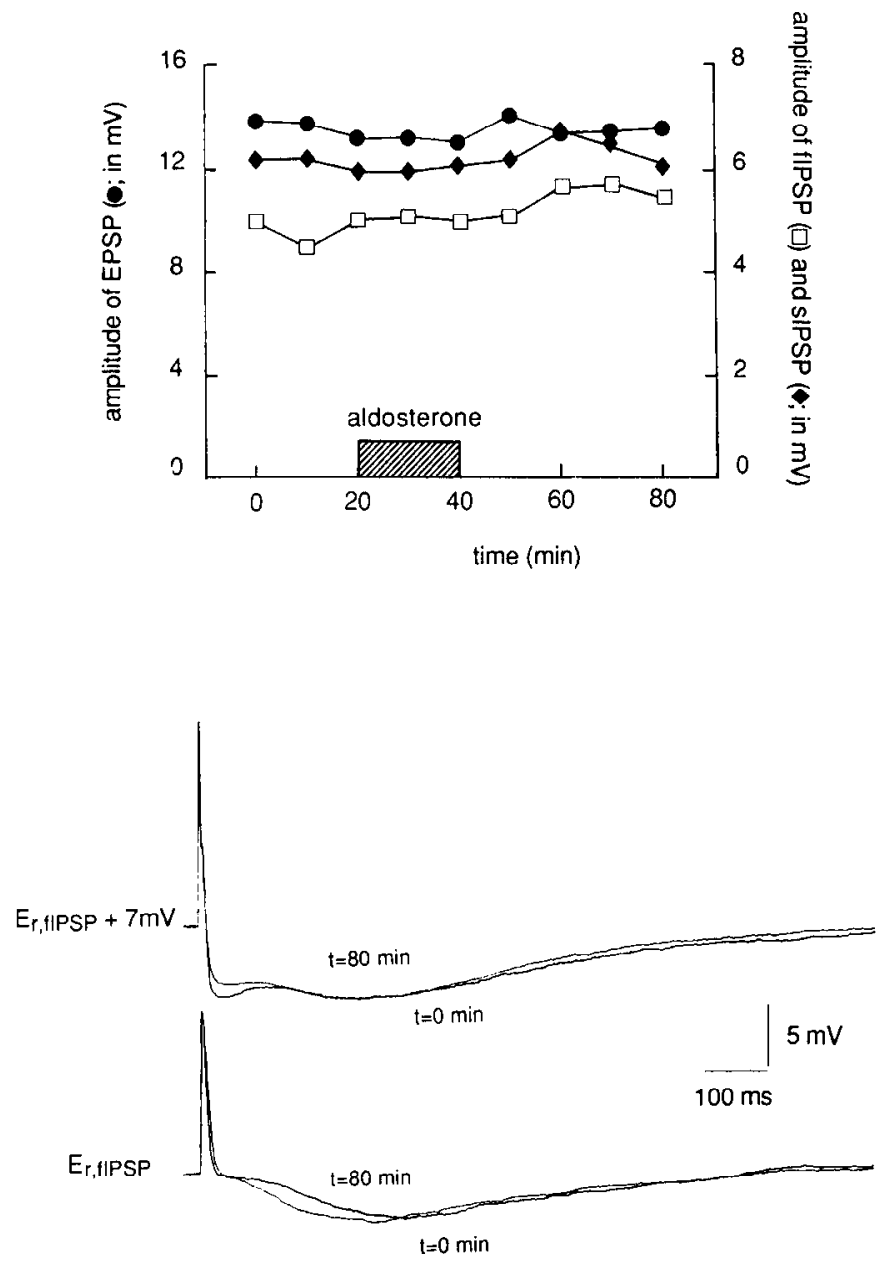

Figure 6. Effect of aldosterone application on synaptic responses. Top, Example of the synaptic responses over time of a CAl pyramidal neuron in an aldosterone-treated slice from an ADX rat. The amplitude of the maximal EPSP (๑) recorded at $E_{r, \text { IPSP }}$ and of the fIPSP ( $\square$ ) and sIPSP $(\diamond)$ recorded at $E_{r, n \mathrm{PS}}+7$ remained stable over the entire recording period. The firing probability also remained stable $(1,0.75$, and 1 at $t$ $=0,40$, and $80 \mathrm{~min}$, respectively), as did the input resistance $(42,41$, and $46 \mathrm{M} \Omega$, respectively, at $t=0,40$, and $80 \mathrm{~min}$ ). Bottom, Representative synaptic responses obtained in this cell before and $1 \mathrm{hr}$ after a 20 min application of $3 \mathrm{~nm}$ aldosterone.

\section{Discussion}

In this article we describe steroid-mediated actions on synaptically evoked firing and on the amplitudes of EPSPs, fIPSPs, and sIPSPs in CAl pyramidal neurons. We observed that in slices from ADX animals synaptic responses were seemingly very similar to the responses in slices from sham-operated controls and to responses described previously in literature for naive animals (for review, see Nicoll ct al., 1990). Thcreforc, possible changes in synaptic circuitry secondary to the adrenalectomy (Sloviter et al., 1989; Gould et al., 1990) do not seem to affect the responses. However, if the slices were repeatedly stimulated, neurons impaled with a microelectrode gradually became unable to respond to this stimulation with an action potential. A $4 \mathrm{~d}$ post-ADX period seems to be critical for the development of this synaptic instability; thus, we recently observed with extracellular field potential recording in the same experimental preparation that synaptically induced population spikes decay after repeated electrical stimulation in slices from $4-7 \mathrm{~d}$ but not $2 \mathrm{~d}$ ADX rats (Joëls and Fernhout, 1993).

The presently described decrease in firing probability of action potentials was not accompanied by changes in input resistance or in the reversal potential for the fIPSP, our reference point for synaptic stimulation. It also was not due to a change in the firing thrcshold, since action potentials evoked in the same neuron with current injection were not attenuated. The accompanying decrease in the EPSP amplitude was relatively small and not significant. However, we cannot exclude that at the threshold for induction of action potentials a small decrease in the EPSP amplitude results in a relatively large decrease in the number of synaptically evoked spikes. Attenuation of the induction of spikes may in turn reduce the feedback inhibition in the CAI area. Accordingly, the sIPSP amplitude decreased significantly over time. However, the decrease in sIPSP amplitude cannot be fully attributed to the attenuation of action potentials, since (1) the fIPSP did not decrease in parallel with the sIPSP and (2) the sIPSP amplitude was also (though less clearly) decreased at $E_{\text {r.npsp }}$, where from the start of the experiment no action potentials were evoked by synaptic stimulation.

We wondered why CA1 pyramidal cells of ADX rats, when repcatedly "challenged," failed to transmit the synaptic signal. It seems unlikely that the in vitro conditions per se cause the

Table 1. Long-term effects of corticosteroid hormones on synaptic and nonsynaptic properties

\begin{tabular}{|c|c|c|c|c|c|c|c|c|c|c|c|}
\hline & $V_{m}$ & $R_{\text {in }}$ & AHP & Accom & $\begin{array}{l}\text { EPSP } \\
(\max )\end{array}$ & $\begin{array}{l}\text { flPSP } \\
\left(\text { at } E_{r}+7\right)\end{array}$ & $\begin{array}{l}\text { slPSP } \\
\left.\text { (at } E_{r}+7\right)\end{array}$ & $E_{r}$ & TS & $\begin{array}{l}\text { MG/ } \\
\text { GR }\end{array}$ & $n$ \\
\hline $\mathrm{ADX}$ & $-67.0 \pm 0.4$ & $45.2 \pm 1.2$ & $3.7 \pm 0.3$ & $5.3 \pm 0.2$ & $12.7 \pm 0.4$ & $4.4 \pm 0.2$ & $6.3 \pm 0.3$ & $-72.8 \pm 0.4$ & $0.53 \pm 0.03$ & $-1-$ & 52 \\
\hline SHAM & $-68.5 \pm 0.8$ & $47.0 \pm 2.1$ & $5.9 \pm 0.7^{*}$ & $4.6 \pm 0.2$ & $13.2 \pm 0.6$ & $4.8 \pm 0.2$ & $6.6 \pm 0.4$ & $-72.4 \pm 0.6$ & $0.85 \pm 0.09^{*}$ & $+/ \pm$ & 21 \\
\hline $\begin{array}{l}\text { ADX/ } \\
\text { RU28362 }\end{array}$ & $-65.7 \pm 1.0$ & $50.3 \pm 2.8$ & $6.1 \pm 0.7^{*}$ & $5.3 \pm 0.3$ & $14.0 \pm 0.9$ & $5.2 \pm 0.3$ & $6.7 \pm 0.3$ & $-73.1 \pm 1.1$ & $0.97 \pm 0.09^{*}$ & $-1+$ & 7 \\
\hline $\begin{array}{l}\text { ADX/ } \\
\text { CORT } \\
\text { ADX// }\end{array}$ & $-66.2 \pm 0.6$ & $48.8 \pm 3.5$ & $6.6 \pm 0.7^{*}$ & $5.7 \pm 0.6$ & $13.1 \pm 0.9$ & $4.5 \pm 0.4$ & $6.7 \pm 0.6$ & $-73.3 \pm 0.3$ & $0.59 \pm 0.09$ & $+/+$ & 12 \\
\hline ALDO & $-65.6 \pm 1.1$ & $45.4 \pm 2.3$ & $2.8 \pm 0.4$ & $5.7 \pm 0.8$ & $14.7 \pm 1.0$ & $4.0 \pm 0.4$ & $4.8 \pm 0.6$ & $-73.4 \pm 1.0$ & $0.44 \pm 0.09$ & $+1-$ & 8 \\
\hline
\end{tabular}

The synaptic and nonsynaptic responses in CA1 neurons were recorded before steroid treatment (ADX) or 1-4 hr after a 20 min perfusion with $30 \mathrm{~nm}$ RU 28362 (RU28362), $30 \mathrm{nM}$ corticosterone (CORT), or $3 \mathrm{~nm}$ aldosterone (ALDO). We also recorded properties of neurons in slices from sham-operated rats (SHAM). The following nonsynaptic properties were routinely recorded (1) resting membrane potential ( $V_{m}$, in mV), (2) input resistance $\left(R_{\text {in }}\right.$, in $\mathrm{M} \Omega$ ), (3) the amplitude of the AHP following a $0.5 \mathrm{nA}$ depolarizing current pulse of $50 \mathrm{msec}$ duration (AHP, in $\mathrm{mV}$ ), and (4) the number of spikes evoked by a $0.5 \mathrm{nA}$ depolarizing current pulse of 500 msec duration (Accom). In addition, we established synaptic properties: (1) the amplitude of the EPSP evoked at $E_{\text {r.fpsp }}$ with maximal current intensity (EPSP, in mV), $(2,3)$ the amplitude of the flPSP and slPSP at $\mathrm{E}_{\mathrm{r} \text { frps }}+7$ (flPSP and sIPSP, respectively, in $\mathrm{mV}$ ), (4) the amplitude of the TS between the peak of the flPSP and slPSP (TS, in $\mathrm{mV}$ ), and (5) the reversal potential for the flPSP $\left(E_{r}\right.$, in $\left.\mathrm{mV}\right)$. We have also indicated the putative MR and GR occupation for the different groups. All data are mean \pm SEM for $n$ neurons. For each parameter we applied a one-way ANOVA. If the test indicated that not all groups were equal, we subsequently tested each of the steroid-treated groups against the nontreated ADX controls with an unpaired $t$ test; ${ }^{*}, p<0.05$. 

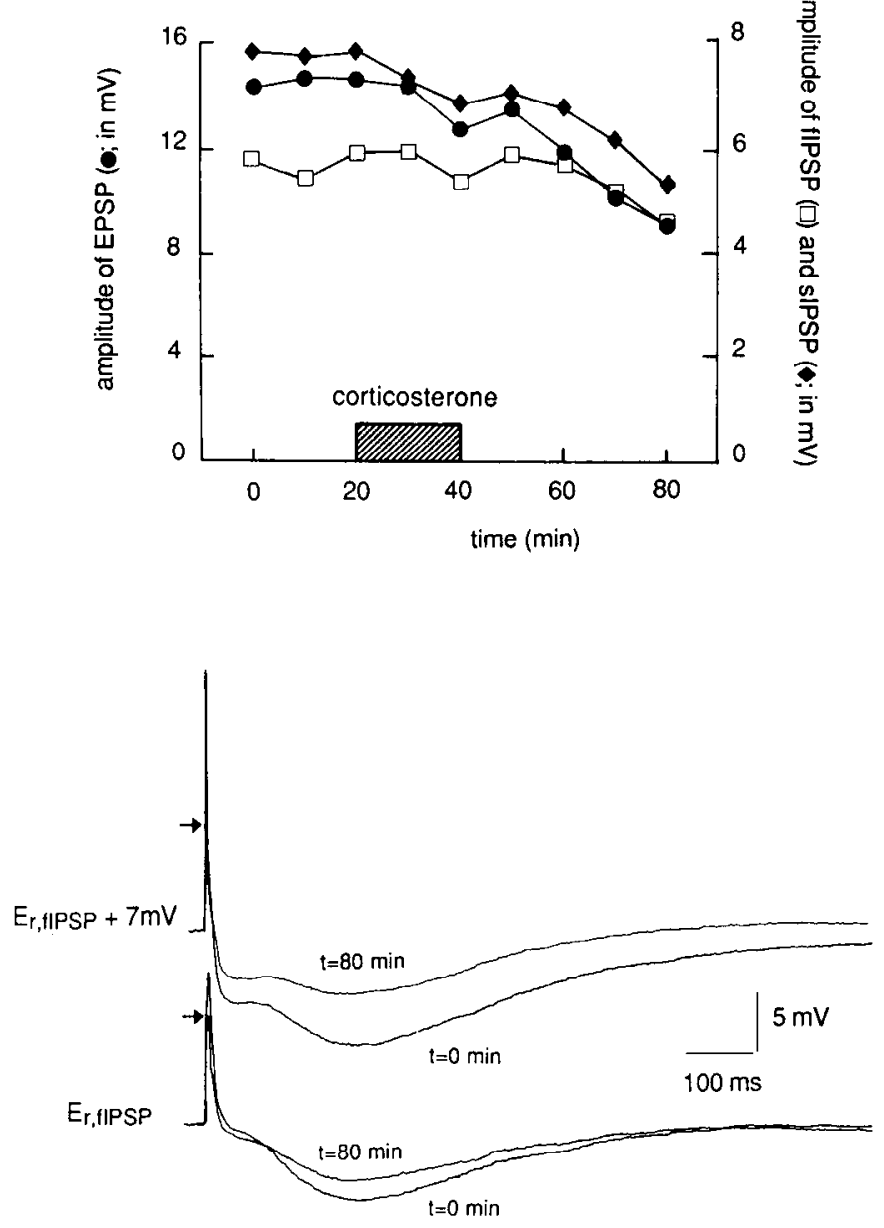

Figure 7. Effect of corticosterone treatment on synaptic responses. Top, Synaptic responses recorded during an $80 \mathrm{~min}$ recording session in a CAl pyramidal neuron that was treated for $20 \mathrm{~min}$ with $30 \mathrm{nM}$ of corticosterone. Particularly the amplitudes of the maximal EPSP and sIPSP declined over time. The probability for inducing a synaptically evoked action potential was reduced from 1 at $t=0 \min$ to 0 at $t=40$ and $80 \mathrm{~min}$; the input resistance changed from $37 \mathrm{M} \Omega$ at $t=0$ to 38 and $44 \mathrm{M} \Omega$ at $t=40$ and $80 \mathrm{~min}$, respectively. Bottom, The reduction of the EPSP and sIPSP amplitudes and the probability for inducing synaptically evoked action potentials is also obvious from the representative synaptic responses obtained in the samc cell beforc and $\mathrm{l} \mathrm{hr}$ after a $20 \mathrm{~min}$ application of corticosterone.

decreased effectiveness of synaptic transmission over time, since CAl cells in slices that were incubated for more than $6 \mathrm{hr}$ showed initially "normal" synaptic responses, which then decayed after repeated stimulation. It is possible that the glucose metabolism in ADX slices is disturbed such that energy-dependent processes slowly fail to work. This is corroborated by the finding that local cerebral glucose utilization is increased in acutely ADX rats (Kadekaro et al., 1988).

Interestingly, the decreased effectiveness of synaptic transmission could be largely prevented if the slice was exposed to $3 \mathrm{~nm}$ aldosterone for $20 \mathrm{~min}$. This concentration of the mineralocorticoid was previously shown to induce long-term MRmediated actions (Joëls et al., 1991). Based on binding studies we assume that most of the MRs and not all of the GRs will be occupicd by $3 \mathrm{~nm}$ aldosterone (Reul and de Koet, 1985). There fore, occupation of at least the MRs seems to be essential for

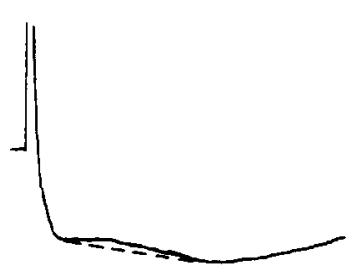

control

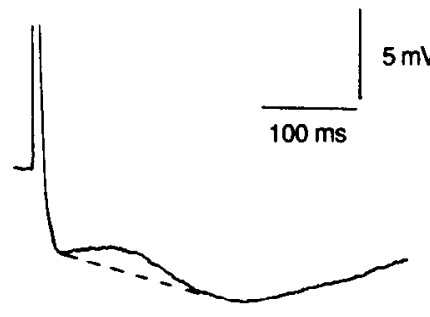

+ RU 28362
Figure 8. Steroid-mediated actions on the depolarizing shift between the fIPSP and sIPSP. The depolarizing shift between the fIPSP and sIPSP is markedly increased at $2 \mathrm{hr}$ after a $20 \mathrm{~min}$ application of 30 nM RU 28362 (right) when compared to a different neuron recorded in the same slice before steroid application (left).

the maintenance of synaptic transmission in the CAl area, as was previously already proposed (Joëls and de Kloet, 1992).

If not only MRs but also GRs were fully occupied, using 30 nM corticosterone (Reul and de Kloet, 1985), the synaptic efficacy decreased again. In this case, EPSP amplitudes were clearly diminished, as well as the firing probability for synaptically evoked action potentials. These effects are rather independent of the MR occupation since the selective GR agonist RU 28362 was also able to reduce EPSP amplitude and synaptic firing. Therefore, the transmission of synaptic signals in the CAl area seems to be optimal in a situation where most of the MRs but not all of the GRs are occupied. Transmission is less efficient when either no steroid receptors are occupied or both MRs and GRs are occupied at the same time. This observation fits with a recent study by Bennett et al. (1991) showing that the development of primed burst potentiation in anesthetized rats was optimal with moderate serum corticosterone levels, as opposed to very high or low corticosterone levels. This could mean that under "average steroid conditions" for the rat (Dallman et al., 1987), transmission of excitatory and inhibitory signals is optimal, while under conditions of increased adrenocortical activity, for example, after stress, synaptic efficacy is temporary diminished. Extremely high steroid levels $(>1 \mu \mathrm{M})$ may specifically diminish the synaptic inhibition (Zeise et al., 1992), potentially leading to excitotoxicity (Sapolsky et al., 1988; Elliot and Sapolsky, 1991).

Previously, we have shown that MR and GR occupation induces changes in current- or transmitter-induced rcsponses of CAl neurons, with a delay of at least $1 \mathrm{hr}$ (Joëls and de Kloet, 1989, 1990; Joëls et al., 1991). If we used a similar protocol to compare synaptic responses before steroid application with responses in other neurons tested $1-4 \mathrm{hr}$ after steroid treatment, we observed only a difference in the amplitude of the TS between the fIPSP and sIPSP. Thus, the TS in slices from sham-operated animals or ADX slices treated with RU 28362, on the one hand, was increased, compared to the untreated ADX slices or slices receiving aldosterone on the other hand. Many processes may underlie the long-term GR-dependent change in the TS. First, the kinetics of the fIPSP and sIPSP may have been changed, resulting in an altered shape of the transition between these two synaptic potentials. To establish this we will have to investigate the shape of pharmacologically isolated fIPSP and sIPSP separately. Second, a depolarizing shift in the IPSP has been attributed to a dendritic, extrasynaptic $\mathrm{GABA}_{\mathrm{A}}$ reccptor-mcdiated response (Alger and Nicoll, 1982a). It is feasible that steroids 
affect this extrasynaptic GABA response in particular. Third, a similar TS in thalamic relay neurons has been ascribed to a $\mathrm{Ca}-$ dependent process in the dendrites (Roy et al., 1984). A steroiddependent increase in such a Ca-dependent process would fit with the GR-mediated increase in the Ca-sensitive $\mathrm{K}$ conductancc associated with the slow AHP. However, as we have shown that the slow AHP is not evoked by depolarizations with the duration of an EPSP and a single action potential, it seems unlikely that steroid-mediated changes in the slow AHP directly underlie the steroid-dependent effect on the TS.

In contrast to the changes in amplitude of the TS and AHP, the amplitudes of the EPSP, fIPSP, and sIPSP recorded with this protocol $1-4$ hr after steroid application were essentially the same as before steroid application. Clearly, we are aware that "between-cell" comparisons for synaptic efficacy, even when performed with the same electrodes and in the same slice, are not very accurate, since relative positions of stimulating and recording electrodes vary among cells. Yet, if these variations are randomly distributed, one should not expect much difference in required stimulus strengths before or after steroid application in the same slice, as was indeed observed.

How may all these stcroid-dependent changes in synaptic transmission add to the phenomena previously observed in the extracellular field potential studies? Both under conditions of no receptor occupation and with high corticosterone levels, synaptic firing was affected to a larger extent than the EPSP amplitude. This would lead to steroid actions on the population spike rather than the compound EPSP, as was indeed observed in all studies (Reiheld et al., 1984; Vidal et al., 1986; Rey et al., 1987). Furthermore, in slices from ADX rats one may expect a gradual decline in the population spike amplitude, which we indeed observed (Joëls and Fernhout, 1993). Such a decline may be inferred from the data from Reiheld et al. (1984), but was not found in the BALB/c mice (Rey et al., 1987). The weaker synaptic transmission over time may partly underlie the observation that the population spike in the dorsal hippocampus from ADX rats was small compared to the rats with an intact pituitary-adrenal axis (Doi et al., 1991). Occupation of the MRs as established with low to moderate amounts of corticosterone may be expected to improve the population spike, as was indeed found by us (Joëls and Fernhout, 1993) and others (Reiheld et al., 1984; Rey et al., 1987, 1989). Finally, additional occupation of the GR, as induced with high corticosterone levels in ADX and sham-operated rats, will reduce the synaptic efficacy and therefore population spike in the CAl area (Vidal et al., 1986; Rey et al., 1987, 1989). The steroid-induced changes are not due to actions on the resting membrane potential, input resistance, or spike threshold. Instead, they may be due to altered pre-and/or postsynaptic amino acid-mediated processes, changes in energy-dependent processes, or altered voltage-dependent ionic conductances.

The steroid actions on amino acid-mediated transmission are usually visible within $20 \mathrm{~min}$ after the steroid application is started and may therefore represent a nongenomic event mediated by membrane receptors (Orchinik et al., 1991). Although these changes are rapid and quite short-lived, when for instance compared with the present and previously observed actions on the AHP amplitude (Joëls and de Kloet, 1989, 1990), they are slow when compared to the effects of $5 \alpha$-reduced steroids on $\mathrm{GABA}_{\mathrm{A}}$ receptor-mediated actions (Majewska et al., 1986; Lambert et al., 1990). Yet, they provide a novel pathway by which the animal can adapt its synaptic transmission in the CAl area to environmental challenges, in a relatively rapid but not very long-lasting way.

\section{References}

Alger BE, Nicoll RA (1982a) Feed-forward dendritic inhibition in rat hippocampal pyramidal cells studied in vitro. J Physiol (Lond) 328: $105-123$

Alger BE, Nicoll RA (1982b) Pharmacological evidence for two kinds of GABA receptor on rat hippocampal pyramidal cells studied in vitro. J Physiol (Lond) 328:125-141.

Arriza JI, Weinberger C, Cerelli G, Glaser TM, Handelin BL, Hausman DE, Evans RM (1987) Cloning of human mineralocorticoid receptor complementary DNA; structural and functional kinship with the glucocorticoid receptor. Science 237:268-275.

Bennett MC, Diamond DM, Fleshner M, Rose GM (1991) Serum corticosterone level predicts the magnitude of hippocampal primed burst potentiation and depression in urethane-anesthetized rats. Psychobiology 19:301-307.

Dallman MF, Akana SF, Cascio CS, Darlington DN, Jacobson L, Levin N (1987) Regulation of ACTH secretion: variation on a theme of B. Prog Horm Res 43:113-173.

de Kloet ER (1991) Brain corticosteroid receptor balance and homeostatic control. In: Frontiers in neuroendocrinology (Ganong WF, Martini L, eds), pp 95-165. New York: Raven.

Dingledine R, Gjerstad L (1980) Reduced inhibition during epileptiform activity in the in vitro hippocampal slice. J Physiol (Lond) 305:297-313.

Doi N, Miyahara S, Hori N (1991) Glucocorticoids promote localized activity of rat hippocampal CAl pyramidal neurones in brain slices. Neurosci Lett 123:99-101.

Elliot E, Sapolsky R (1991) Glucocorticoids, neurotoxicity and calcium regulation. In: Fidia research symposium, Neurosteroids and brain function (Costa E, Paul SM, eds), pp 47-54. New York: Thieme.

Funder JW, Pearce PT, Smith R, Smith AI (1988) Mineralocorticoid action: target-tissue specificity is enzyme, not receptor, mediated. Science 242:583-585.

Gould E, Wooley C, McEwen BS (1990) Short-term glucocorticoid manipulations affect neuronal morphology and survival in the adult dentate gyrus. Neuroscience 37:367-375.

Gustafsson B, Wigstrom H (1981) Evidence for two types of afterhyperpolarization in CAl pyramidal cells in the hippocampus. Brain Res 206:462-468.

Hotson JR, Prince DA (1980) A calcium-activated hyperpolarization follows repetitive firing in hippocampal neurons. J Neurophysiol 43; $409-419$.

Joëls M, de Kloet ER (1989) Effects of glucocorticoid and norepinephrine on the excitability in the hippocampus. Science 245:15021505.

Joëls M, de Kloet ER (1990) Mineralocorticoid receptor-mediated changes in membrane properties of rat CAl pyramidal neurons in vitro. Proc Natl Acad Sci USA 87:4495-4498.

Joëls M, de Kloet ER (1992) Control of neuronal excitability by corticosteroid hormones. Trends Neurosci 15:25-30.

Jöels M, Fernhout B (1993) Decreased population spike in CAl hippocampal area of adrenalectomized rats after repeated synaptic stimulation $\mathrm{J}$ Neuroendocrinol, in press.

Joëls M, Hesen W, de Kloet ER (1991) Mineralocorticoid hormones suppress serotonin-induced hyperpolarization of rat hippocampal CA 1 neurons. J Neurosci 11:2288-2294.

Kadekaro M, Ito M, Gross PM (1988) Local cerebral glucose utilization is increased in acutely adrenalectomized rats. Neuroendocrinology 47:329-334.

Karst H, Joëls M (1991) The induction of corticosteroid actions on membrane properties of hippocampal CA 1 neurons requires protein synthesis. Neurosci Lett 130:27-31.

Kerr DS, Campbell LW, Hao S-Y, Landfield PW (1989) Corticosteroid modulation of hippocampal potentials: increased cffect with aging. Science 245:1505-1507.

Knowles WD, Schwartzkroin PA (1981) Local circuit synaptic interactions in hippocampal brain slice. $J$ Neurosci 1:318-322.

Lambert JJ, Peters JA, Sturgess NC, Hales TG (1990) Steroid modulation of the GABAa receptor complex: electrophysiological studies. In: Ciba Foundation symposium 153, Steroids and neuronal activity, pp 56-71. Wiley: Chichester. 
Lancaster B, Nicoll RA (1987) Properties of two calcium-activated hyperpolarizations in rat hippocampal neurons. J Physiol (Lond) 389: 187-203.

Lopes de Silva FH, Witter MP, Boeijinga PH, Lohman AHM (1990) Anatomic organization and physiology of the limbic cortex. Physiol Rev 70:453-511.

Majewska MD, Harrison NL, Schwartz RD, Barker JL, Paul SM (1986) Steroid hormone metabolites are barbiturate-like modulators of the GABA receptor. Science 232:1004-1007.

McEwen BS, de Kloet ER, Rostene W (1986) Adrenal steroid receptors and actions in the nervous system. Physiol Rev 66:1121-1188.

Nicoll RA, Malenka RC, Kauer JA (1990) Functional comparison of neurotransmitter receptor subtypes in mammalian central nervous system. Physiol Rev 70:513-565.

Orchinik M, Murray TF, Moore FL (1991) A corticosteroid receptor in neuronal membranes. Science 252:1848-1851.

Philibert D, Moguilevski M (1983) RU 28362, a useful tool for the characterization of glucocorticoid and mineralocorticoid receptors. Proc Annu Meet Endocr Soc 65:335.

Ratka A, Sutanto W, de Kloet ER (1988) Long-term glucocorticoid suppression of opioid-induced antinociception. Neuroendocrinology 48:439-444.

Reiheld CT, Teyler TJ, Vardaris R (1984) Effects of corticosterone on the electrophysiology of hippocampal CA1 pyramidal cells in vitro. Brain Res Bull 12:349-353.

Reul JMHM, de Kloet ER (1985) Two receptor systems for corticosterone in rat brain: microdistribution and differential occupation. Endocrinology 117:2505-2512.

Rey M, Carlier E, Soumireu-Mourat B (1987) Effects of corticosterone on hippocampal slice electrophysiology in normal and adrenalectomized BALB/c mice. Neuroendocrinology 46:424-429.

Rey M, Carlier E, Soumireu-Mourat B (1989) Effect of RU 486 on hippocampal slice electrophysiology in normal and adrenalectomized BALB/c mice. Neuroendocrinology 49:120-125.

Roy JP, Clercq M, Steriade M, Deschenes M (1984) Electrophysiology of neurons of lateral thalamic nuclei in cat: mechanisms of long-lasting hyperpolarizations. J Neurophysiol 51:1220-1235.

Sapolsky RM, Packan DR, Vale WW (1988) Glucocorticoid toxicity in the hippocampus: in vitro demonstration. Brain Res 453:367-371.

Schwartzkroin PA (1975) Characteristics of CA1 neurons recorded intracellularly in the hippocampal in vitro slice preparation. Brain Res 85:423-436.

Sloviter R, Valiquette G, Abrams G, Ronk E, Sollas A, Paul L, Neubort S (1989) Selective loss of hippocampal granule cells in the mature rat brain after adrenalectomy. Science 243:535-538.

Talmi M, Carlier E, Rey M, Soumireu-Mourat B (1992) Modulation of the in vitro electrophysiological effect of corticosterone by extracellular calcium in the hippocampus. Neuroendocrinology 55:257263.

van Eekelen JAM, Jiang W, de Kloet ER, Bohn MC (1988) Distribution of the mineralocorticoid and glucocorticoid receptor mRNAs in the rat hippocampus. J Neurosci Res 21:88-94.

Vidal C, Jordan W, Zieglgansberger W (1986) Corticosterone reduces the excitability of hippocampal pyramidal cells in vitro. Brain Res 383:54-59.

Zcise ML, Teschemacher A, Arragada J, Zieglgansberger W (1992) Corticosterone reduces synaptic inhibition in rat hippocampal and neocortical neurons in vitro. J Neuroendocrinology 4:107-113. 